\title{
Extract Transform Loading Data Absensi STMIK STIKOM Indonesia Menggunakan Pentaho
}

\author{
Ni Wayan Sumartini Saraswati ${ }^{1}$, Ni Made Lisma Martarini ${ }^{2}$ \\ Program Studi Teknik Informatika, STMIK STIKOM Indonesia \\ Denpasar, Bali, Indonesia, \\ E-Mail:1 sumartini.saraswati@stiki-indonesia.com, ${ }^{2}$ lismamartarini@gmail.com
}

\begin{abstract}
ABSTRAK
Proses Absensi STMIK STIKOM Indonesia saat ini telah menggunakan mesin pengenalan sidik jari. Seperti kita ketahui bersama output dari mesin pengenalan sidik jari telah dilengkapi dengan software yang dapat menyajikan laporan absensi. Namun laporan tersebut belum sesuai dengan kondisi kerja di STMIK STIKOM Indonesia. Kondisi yang dimaksud adalah shift kerja yang berubah-ubah, sehingga mengharuskan operator mengubah data shift kerja yang terdapat dalam software setiap perubahan terjadi. Dari segi efektivitas pekerjaan, hal tersebut kurang memadai. Penelitian ini bertujuan untuk menghasilkan laporan absensi yang dibutuhkan oleh manajemen STMIK STIKOM Indonesia serta untuk mendapatkan rancang bangun ETL data absensi yang dapat digunakan sebagai materi pembelajaran pada mata kuliah Data Integration. ETL adalah kependekan dari Extract Transform and Load. Dalam pengertian sederhana, ETL adalah sekumpulan proses untuk mengambil dan memproses data dari satu atau banyak sumber data menjadi sumber baru. Proses ETL yang dilakukan telah berhasil mengolah data absensi yang bersumber dari mesin fingerprint ke dalam laporan rekapitulasi kehadiran, jam kerja kurang, jam kerja lebih dalam sebulan serta laporan rincian absensi yang berisi jumlah jam kerja perharinya.
\end{abstract}

Kata Kunci : ETL, Pentaho, Transformasi, Laporan, Absensi

\begin{abstract}
The STMIK STIKOM Indonesia Attendance Process is currently using a fingerprint recognition machine. As we know, the output of the fingerprint recognition machine has been equipped with software that can present attendance reports. But the report is not suitable with the working conditions at STMIK STIKOM Indonesia. The condition refers to the work shift that often changes, so that requires operators to change the work shift data in the software every change occurs. In terms of work effectiveness, this is inadequate. This study aims to produce the attendance reports needed by the management of STMIK STIKOM Indonesia and to obtain ETL design of attendance data that can be used as learning material in the Data Integration course. ETL is short for Extract Transform and Load. In a simple sense, ETL is a collection of processes to retrieve and process data from one or many data sources into new sources. The ETL process carried out successfully processed attendance data sourced from the fingerprint machine into the recapitulation report of attendance, less working hours, more hours of work in a month and a detailed attendance report containing the number of hours worked per day.
\end{abstract}

\section{Keyword : ETL, Pentaho, Transformation, Report, Attendance}

Author Korespondensi (Ni Wayan Sumartini Saraswati)

Email : sumartini.saraswati@stiki-indonesia.com 


\section{PENDAHULUAN}

STMIK STIKOM Indonesia saat ini memiliki 60 orang dosen penuh waktu dan 61 orang tenaga kependidikan. Dengan karyawan yang berjumlah 121 orang tersebut tentu saja menjadikan permasalahan tersendiri dalam menyajikan laporan kepegawaian salah satunya adalah laporan absensi.

Proses Absensi saat ini telah menggunakan mesin pengenalan sidik jari. Seperti kita ketahui bersama output dari mesin pengenalan sidik jari telah dilengkapi dengan software yang dapat menyajikan laporan absensi. Namun laporan tersebut belum sesuai dengan kondisi kerja di STMIK STIKOM Indonesia. Kondisi yang dimaksud adalah shift kerja yang berubah-ubah, sehingga mengharuskan operator mengubah data shift kerja yang terdapat dalam software setiap perubahan terjadi. Dari segi efektivitas proses kerja hal tersebut kurang memadai untuk pelaksanaannya. Kondisi lainnya adalah format laporan absensi yang dibutuhkan manajemen tidak sesuai dengan laporan absensi versi vendor mesin fingerprint.

Kunci sukses bagi sebuah perusahaan untuk bertahan pada masa sekarang adalah kemampuan untuk menganalisa, merencanakan dan bereaksi terhadap perubahan lingkungan bisnis secara cepat dan akurat. Kemampuan ini hanya dapat dipenuhi dengan tersediannya informasi yang memadai bagi para manajer, direktur dan para pengambilan keputusan lainnya[1]. Informasi adalah fondasi dari setiap keputusan bisnis penting yang dilakukan[2]. Kebutuhan perusahaan untuk mengambil keputusan secara tepat dan cepat berdasarkan fakta pasar menjadi lebih kritis agar dapat bertahan. Hal ini didukung dengan Business Intelligence (BI) di perusahaan[3]. Seperti kita ketahui intelijen bisnis (BI) dianggap memiliki dampak luar biasa pada bisnis. Aktivitas penelitian telah berkembang dalam beberapa tahun terakhir. Bagian penting dari sistem BI adalah Implementasi proses Extract, Transform, dan Load (ETL) yang berkinerja baik[4].

Pentaho adalah nama perusahaan dan juga nama produk. Pentaho mengkhususkan diri sebagai perusahaan pembuat software untuk keperluan data warehouse (DWH) dan business intelligence (BI). Pentaho adalah sebuah software yang digunakan dalam proses ETL dalam penyusunan data warehouse. Elemen utama dari Pentaho Data Integration (PDI) adalah Transformation dan Job. Transformation adalah sekumpulan instruksi untuk merubah input menjadi output yang diinginkan (inputproses-output). Sedangkan Job adalah kumpulan instruksi untuk menjalankan transformasi[5]. Pentaho Community Edition atau Pentaho BI Suite adalah produk dari Pentaho yang sudah terintegrasi dengan kemampuan reporting, dashboard, data mining, workflow, dan ETL [6]. ETL adalah sekumpulan proses untuk mengambil dan memproses data dari satu atau banyak sumber data menjadi sumber baru[7]. ETL adalah proses inti dari integrasi data dan biasanya terkait dengan data warehouse. Tools ETL mengekstrak data dari sumber yang dipilih, mengubahnya menjadi format baru sesuai dengan aturan bisnis, dan kemudian memuatnya ke dalam struktur data target [8]. ETL merupakan proses yang sangat penting dalam data warehouse, dengan ETL inilah data dari operational dapat dimasukkan ke dalam data warehouse[9].

Penelitian ini bertujuan untuk menghasilkan laporan absensi yang dibutuhkan oleh manajemen STMIK STIKOM Indonesia serta untuk mendapatkan rancang bangun ETL data absensi yang dapat digunakan sebagai materi pembelajaran pada mata kuliah Data Integration.

\section{METODOLOGI}

\subsection{Penelitian Terdahulu}

ETL digunakan dalam pengolahan data sains antariksa dimana kajian penerapan metode data warehouse ini diharapkan memberikan solusi dan kemudahan bagi pengelola dalam menyediakan data sains antariksa untuk mendukung kegiatan riset cuaca antariksa [10]. Proses ETL untuk mendukung pembangunan Data Warehouse juga dilakukan untuk membuat sistem pendukung keputusan dalam pengolahan data akademik dan kemahasiswaan perguruan tinggi[11].

Salah satu atribut dalam biodata mahasiswa adalah atribut yang menyimpan informasi tentang asal SMA dari seorang mahasiswa. Informasi tentang asal SMA menjadi salah satu dimensi yang banyak digunakan program studi dalam melakukan evaluasi diri.Persoalan yang terjadi, data yang diisikan pada atribut ini 
banyak yang kotor,bias dan tidak valid sehingga tidak mampu memenuhi kebutuhan pandangan pemakai atas profil mahasiswa sehingga proses ETL atas data ini dibutuhkan[12].

Data warehouse pada umumnya adalah data warehouse tradisional mempunyai beberapa kelemahan yang mengakibatkan kualitas data yang dihasilkan tidak spesifik dan efektif. Sistem semantic data warehouse merupakan solusi untuk menangani permasalahan tersebut dengan kelebihan antara lain: manajeman kualitas data yang spesifik dengan format data seragam untuk mendukung laporan OLAP yang baik, dan performance pencarian informasi yang lebih efektif dengan kata kunci bahasa alami[13]. Tujuan dari perancangan data warehouse yang dibuat adalah untuk melayani informasi strategis seperti jumlah total mahasiswa baru per batch, status mahasiswa, dan jumlah hasil berdasarkan IPK dan predikat. Metode yang umum digunakan dalam pengembangan datawarehouse adalah metode Kimball dengan metodologi sembilan langkah [14].

Proses ETL untuk membangun data warehouse juga diterapkan pada jasa pengiriman. Aplikasi data warehouse dibentuk berdasarkan data-data operasional, diolah dalam berbagai dimensi yang ada, sehingga dapat membentuk suatu laporan guna memenuhi kebutuhan pihak eksekutif akan informasi. [15]. Dalam penelitian yang lain dilakukan pengembangan data warehouse untuk pengolahan data SDM. Sistem dibangun untuk melakukan online analitical processing (OLAP) berbasis web guna mempermudah eksekutif memperoleh informasi[16].

\subsection{Alur Penelitian}

Penelitian ini dikembangkan berdasarkan metodologi rekayasa dengan tahapan penelitian seperti ditunjukkan oleh gambar 1 .

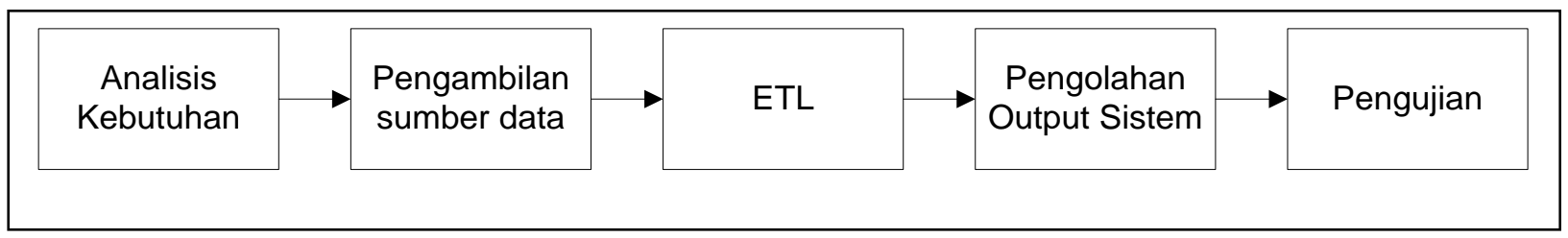

Gambar 1. Tahapan Penelitian

Analisis kebutuhan dilakukan dengan teknik pengumpulan data berdasarkan kebutuhan akan laporan absensi dan format data input yang tersedia. Proses pengambilan sumber data adalah proses extract data log absensi dari mesin sidik jari periode bulanan. Proses ETL adalah proses mengubah data mentah yang bersumber dari log absensi menjadi laporan absensi. Proses pengolahan output sistem adalah proses editing format dan style laporan dalam bentuk file Microsoft Excel. Proses pengujian dilakukan dengan mengambil 30 sampel data secara acak dengan mencocokkan hasil pemrosesan manual dan hasil pemrosesan dengan Pentaho.

\subsection{Teknik Pengumpulan Data}

Pengumpulan data dilakukan dengan metode pengumpulan data primer dan metode pengumpulan sekunder. Metode pengumpulan data primer berupa wawancara dan observasi dilakukan untuk sistem pelaporan absensi STMIK STIKOM Indonesia pada bidang LPTPK. Wawancara dan observasi terutama dilakukan untuk mengetahui secara pasti kebutuhan LPTPK terhadap bentuk dan format laporan absensi. Metode pengumpulan data sekunder dilakukan dengan cara kajian pustaka untuk memahami step/objek dalam pentaho yang dapat digunakan untuk menyelesaikan permasalahan pengolahan data absensi.

\subsection{Gambaran Umum Sistem}

Gambaran umum sistem dalam proposal ini terdiri dari analisa kebutuhan sistem dan DFD. Gambaran umum sistem yang akan dilaksanakan dalam penelitian ini adalah seperti ditunjukkan pada gambar 2 .

\subsection{Analisa Kebutuhan Sistem}

\subsubsection{Format data log absensi}

Format data log absensi yang diambil dari mesin adalah sebagai berikut, seperti ditunjukkan oleh gambar 3. 


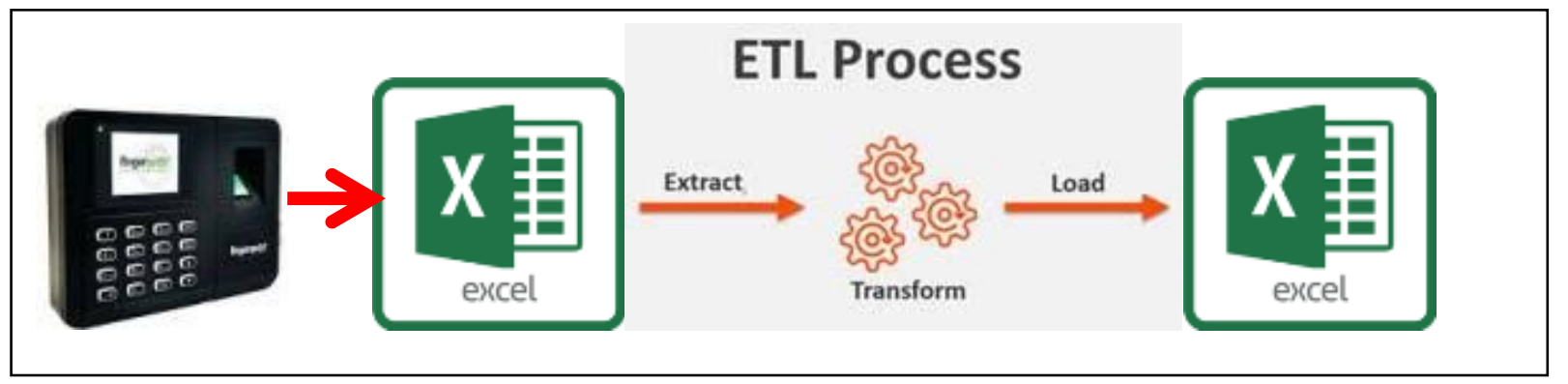

Gambar 2. Tahapan Penelitian

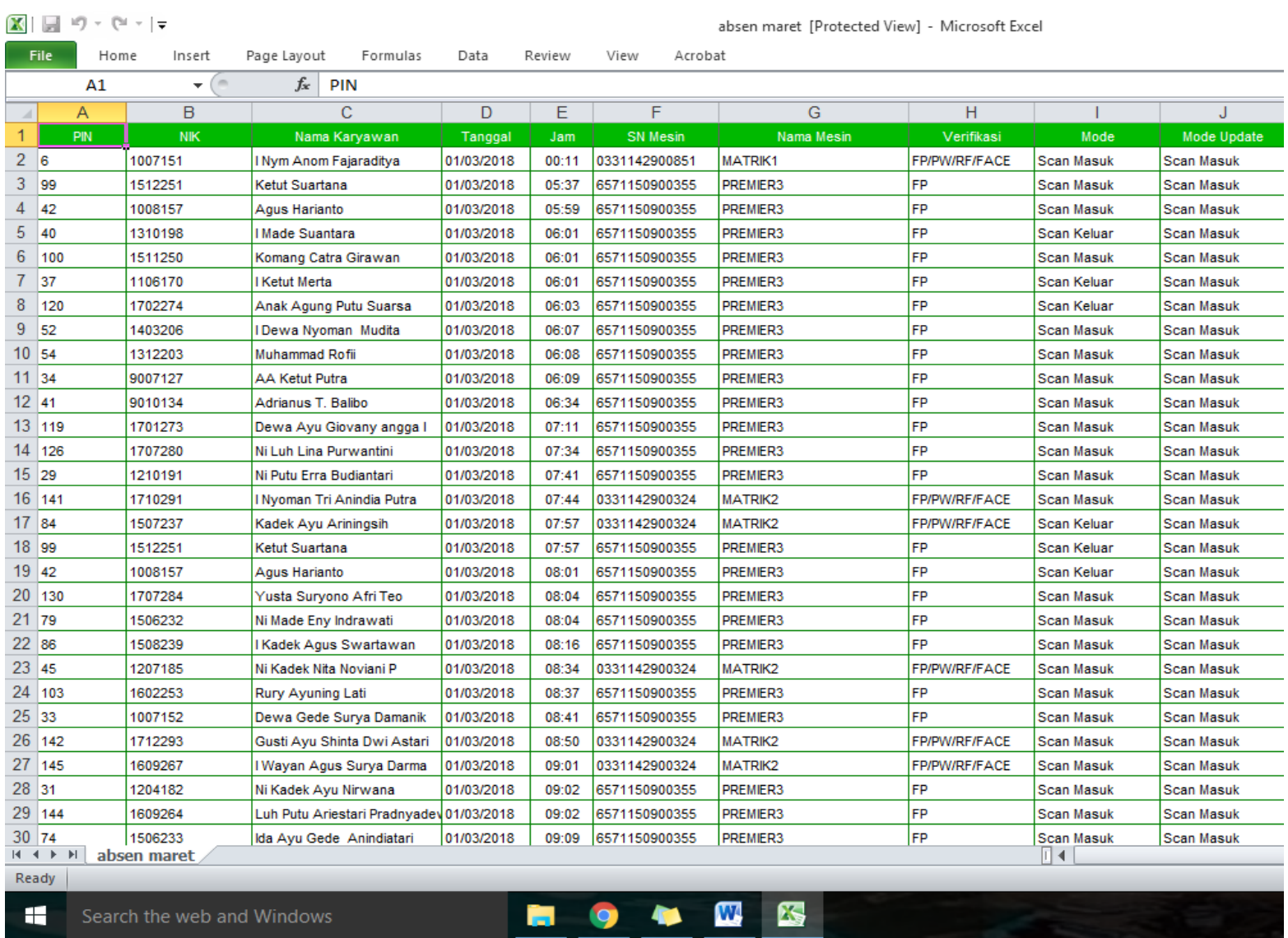

Gambar 3. Format Data Log Absensi

\subsubsection{Format laporan absensi}

Laporan absensi sebagai output proses ETL terdiri dari laporan - laporan berikut ini :

a. Laporan jumlah jam kerja harian.

b. Laporan jumlah kehadiran dalam sebulan

c. Laporan lembur dalam sebulan

d. Laporan kehadiran dengan kekurangan jam dalam sebulan.
2.5.3. Transformasi preprosesing data absensi

Dalam preprocessing data absensi kita akan membuat sebuah file transformation baru yang bisa kita beri nama transformasi jumlah jam. Adapun objek transformasi yang terlibat dalam preprocessing ini adalah Microsoft Excel input, sort rows, dua group by, merge join dan Microsoft Excel output seperti ditunjukkan oleh gambar 4. Tujuan dari transformasi ini adalah menghasilkan record daftar karyawan dengan 
mengambil log absensi terkecil sebagai kolom jam datang dan log absensi terbesar sebagai kolom jam pulang. Sehingga dengan transformasi ini data log yang awalnya terdiri dari beberapa baris untuk tiap karyawan perharinya terangkum menjadi 1 baris data absensi.

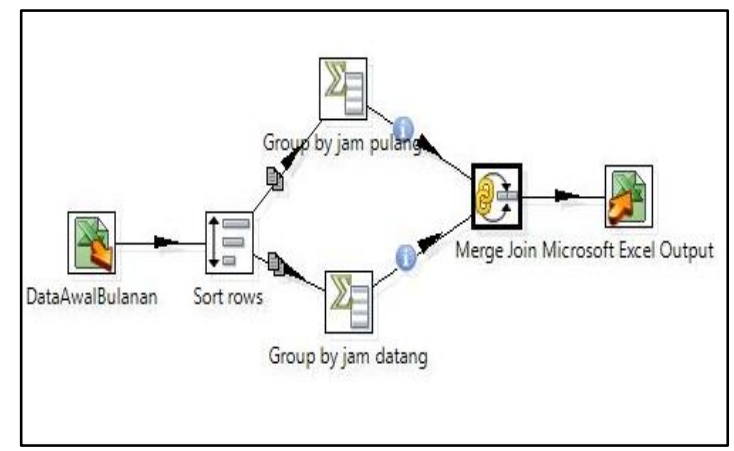

Gambar 4. Detail Transformasi Preprosesing Data Absensi

\subsubsection{Menghitung jumlah jam kerja harian}

Pentaho memiliki sedikit kelemahan dalam operasi tipe variabel timestamp. Sehingga dalam pengurangan jam pulang dengan jam datang untuk memperoleh jumlah jam kerja kita menggunakan bantuan Microsoft Excel. Langkah pertama kita menghapus 2 field yang tidak terpakai yaitu nama karyawan_1 dan tanggal_1. Langkah kedua kita lakukan penghitungan dengan formula jam pulang dikurangi jam kedatangan seperti ditunjukkan gambar 5. Simpan file dengan nama yang sama jumlahjam.xls.

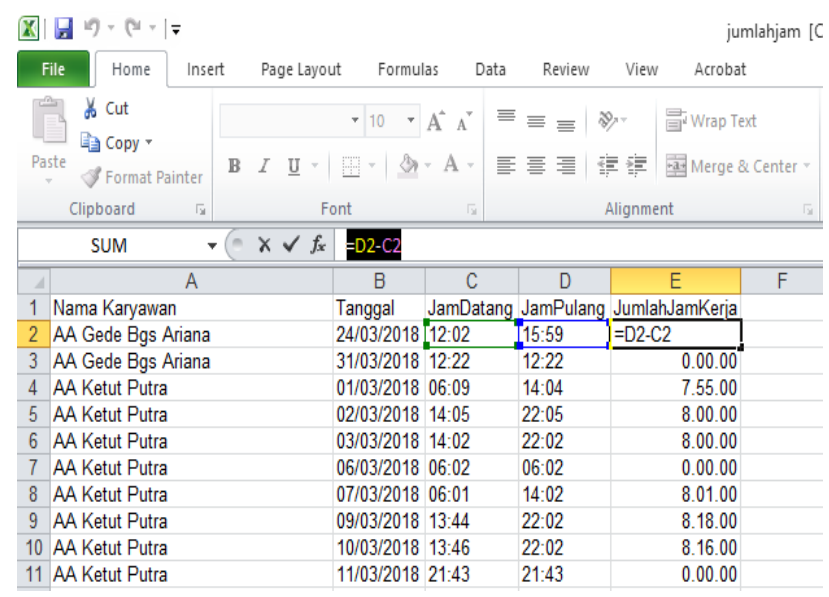

Gambar 5. Operasi Pengurangan Jam Pulang dan Jam Datang

\subsubsection{Transformasi menghitung jumlah}

kurang jam kerja dalam sebulan

Pengolahan selanjutnya bertujuan untuk mengetahui jumlah hari di mana jam kerja kurang dari 8 jam sehari. Dibuatlah transformasi baru dengan dengan nama transformasi jumlah jam kurang. Detail lengkap dari step yang dibutuhkan dalam transformasi ini adalah seperti ditunjukkan oleh gambar 6. Filter akan menyaring record dimana nilai kolom jumlahjamkerja kurang dari 8 jam sehari. Group by akan menghitung berapa record yang dihasilkan oleh filter rows yang akan dikelompokkan per nama karyawan, sehingga dihasilkan dalam sebulan berapa kali seorang karyawan hadir di kantor dengan jumlah jam kerja kurang dari 8 jam.

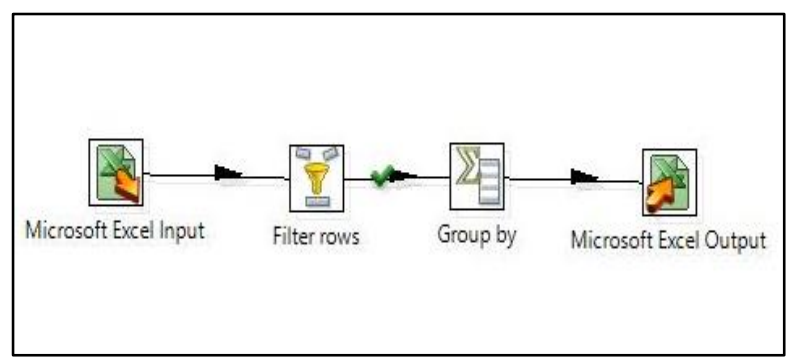

Gambar 6. Detail Transformasi Hitung Jumlah Hari Jam Kerja Kurang

2.5.6. Transformasi menghitung jumlah hari lembur dan jumlah kehadiran dalam sebulan

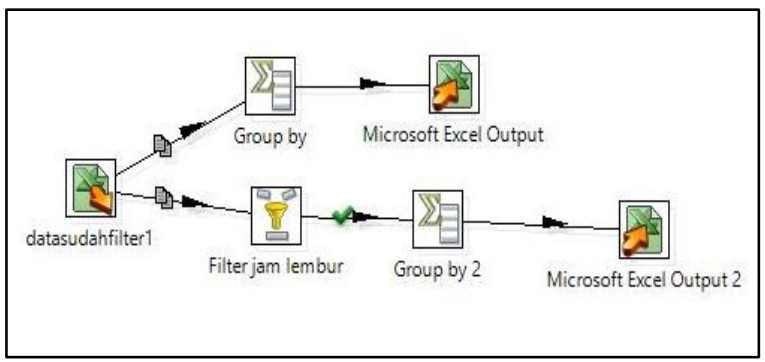

Gambar 7. Detail Transformasi Jumlah Kehadiran dan Jam kerja Lebih per Bulan

Transformasi ini bertujuan untuk menghitung jumlah hari lembur perbulannya dan jumlah kehadiran dalam sebulan. Detail dari transformasi seperti ditunjukkan oleh gambar 7 . Input dari Microsoft Excel input bersumber dari file jumlahjam xls. Filter jam lembur berfungsi untuk menyaring baris record dimana nilai 
kolom jumlahjamkerja lebih dari 8 jam 30 menit. Group by 2 berfungsi untuk menghitung jumlah baris yang dihasilkan filter jam lembur dikelompokkan berdasarkan nama karyawan. Sehingga Microsoft Excel Output 2 akan berisi jumlah kehadiran dimana karyawan bekerja lebih dari 8 jam 30 menit. Group by akan menghitung jumlah record dari file absensi dikelompokkan berdasarkan nama karyawan

\subsubsection{Transformasi laporan rincian absensi}

Laporan rincian absensi menampilkan jumlah jam kerja harian masing - masing karyawan dalam sebulan. Laporan ini dihasilkan dari transformasi laporan rincian absensi seperti ditunjukkan oleh gambar 9. Transformasi ini terdiri dari microsoft excel input, sort rows, row denormaliser dan microsoft excel output. Microsoft excel input bersumber dari file jumlahjam.xls seperti sudah dijelaskan sebelumnya. Sort rows berfungsi untuk mengurutkan data absensi berdasarkan nama karyawan dan tanggal. Row denormaliser berfungsi untuk mengubah tanggal yang awalnya sebagai baris menjadi kolom. Sehingga pada Microsoft excel output dihasilkan file matrik dimana penanda baris record adalah nama karyawan, penanda kolom adalah tanggal dan value sel adalah jumlah jam kerja.

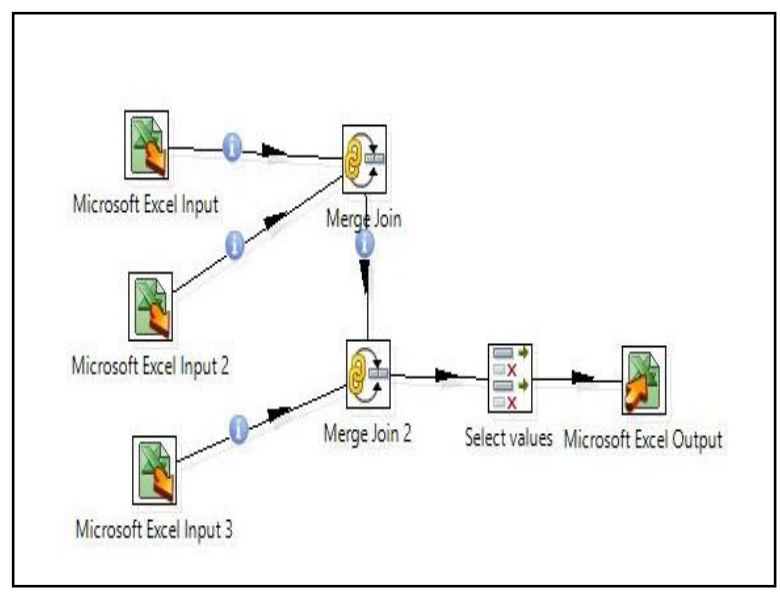

Gambar 8. Detail Transformasi Laporan Akhir sehingga dihasilkan berapa jumlah kehadiran karyawan tersebut dalam sebulan.

\subsubsection{Transformasi laporan akhir absensi}

Laporan akhir absensi bertujuan untuk menggabungkan antara file jumlah jam kerja lembur, jumlah jam kerja kurang dan jumlah kehadiran dalam satu file output. Detail step yang dibutuhkan dalam transformasi ini seperti ditunjukkan oleh gambar 8 .

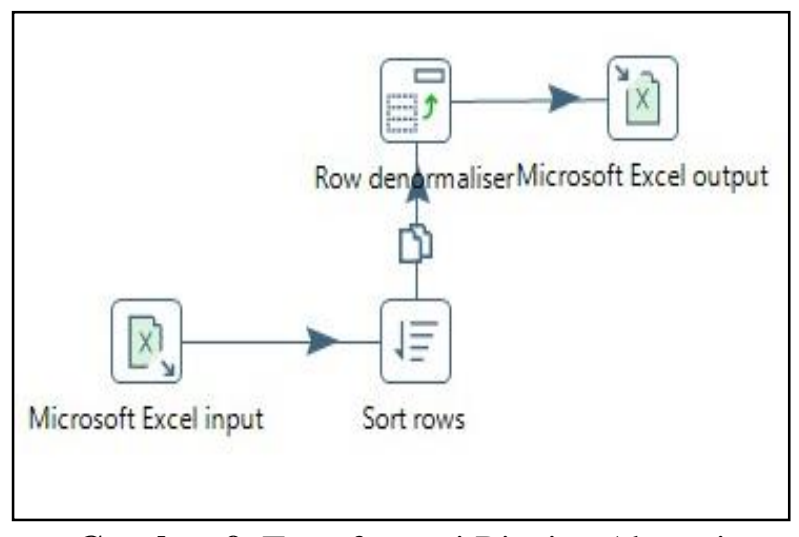

Gambar 9. Transformasi Rincian Absensi

\section{HASIL DAN PEMBAHASAN}

Hasil dari pengolahan data absensi menggunakan pentaho adalah dengan dihasilkannya dua file excel yaitu laporan rekapitulasi jumlah kehadiran dan rincian jumlah jam hadir perhari nya.

\subsection{Laporan Rincian Jumlah Jam Hadir \\ Perhari}

Laporan Jumlah Jam Hadir Perhari adalah Matrik antara nama karyawan dan tanggal dimana valuenya adalah jumlah jam kehadiran perhari seperti ditunjukkan oleh gambar 10 .

\subsection{Laporan Rekapitulasi Jumlah Kehadiran Perbulan}

Laporan Rekapitulasi Jumlah Kehadiran Perbulan merupakan rangkuman dari laporan rincian jumlah jam hadir per hari. Laporan ini terdiri dari jumlah hari dimana karyawan bekerja kurang dari 8 jam, jumlah hari dimana karyawan bekerja lebih dari 8 jam sehari, dan jumlah kedatangan karyawan selama sebulan seperti ditunjukkan oleh gambar 11. 


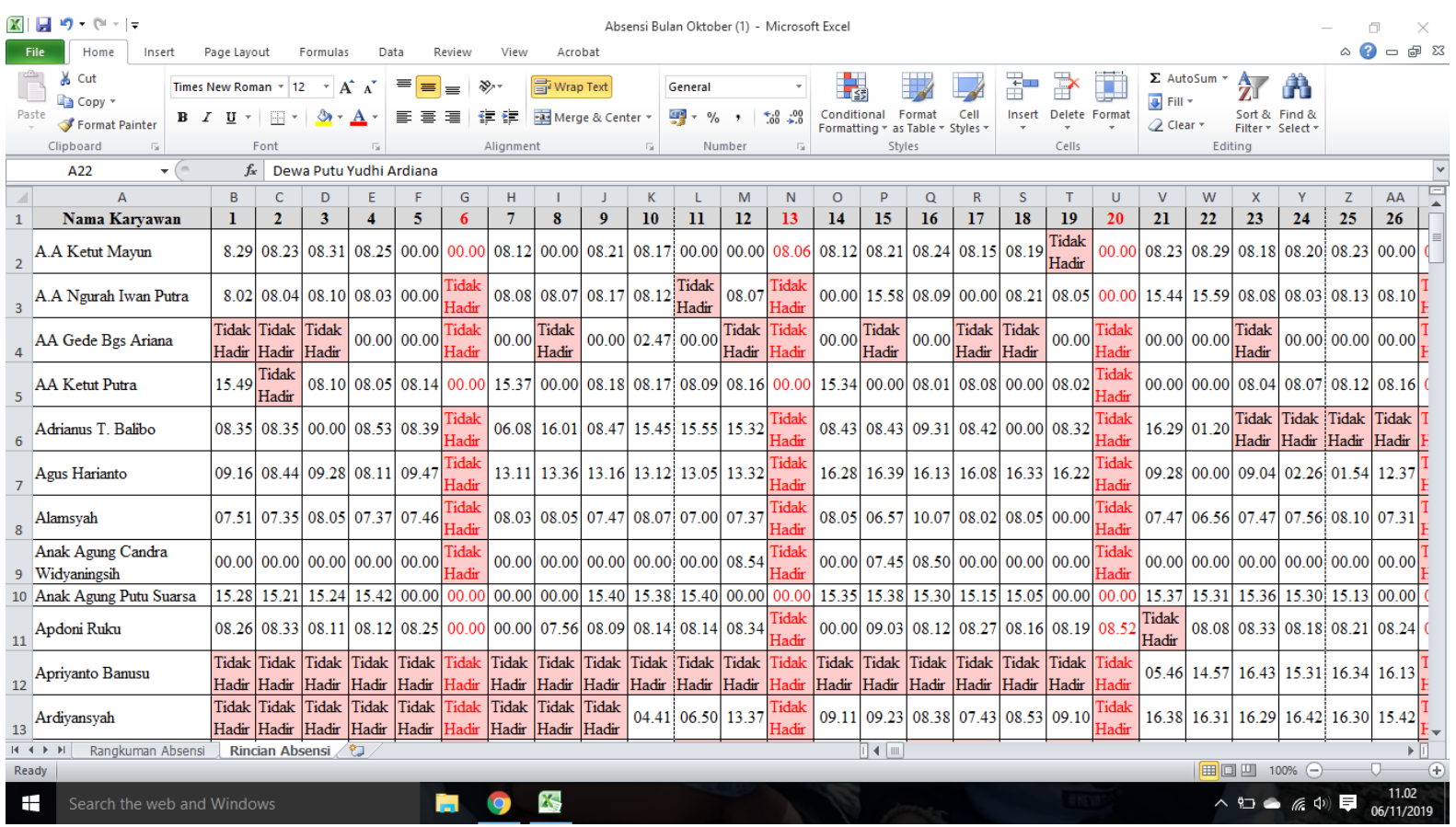

Gambar 10. Laporan rincian jumlah jam hadir perhari

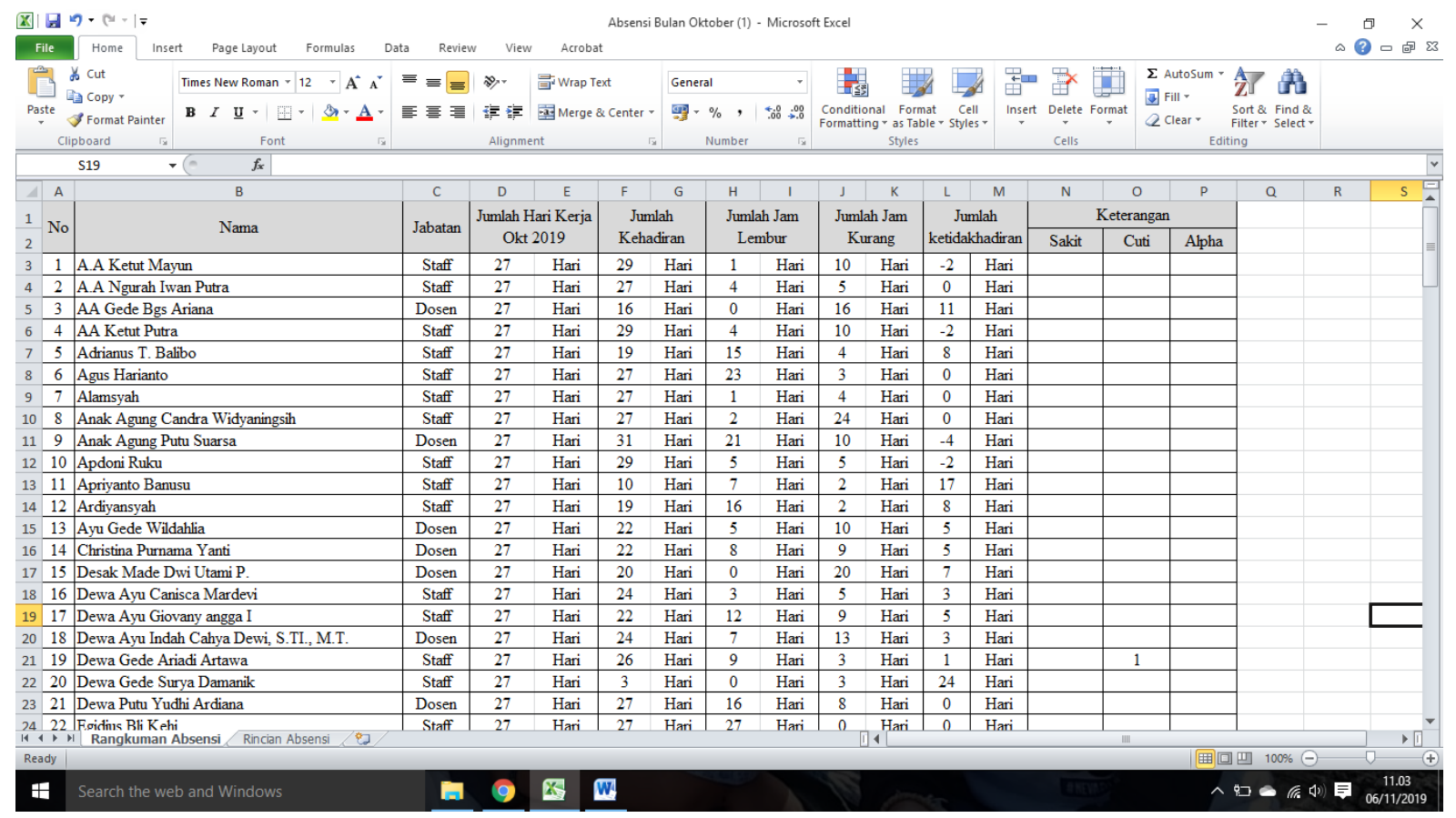

Gambar 11. Laporan Rekapitulasi Jumlah Kehadiran dalam Sebulan 


\section{SIMPULAN DAN SARAN}

\subsection{Kesimpulan}

Berikut simpulan yang bisa didapat dari penelitian untuk pengolahan data absensi menggunakan Pentaho :

1. Untuk menghasilkan laporan sesuai kebutuhan manajemen maka dibutuhkan 5file transformasi yang terpisah.

2. Input sistem adalah file excel luaran dari mesin fingerprint.

3. Output akhir dari sistem yang digunakan oleh manajemen adalah laporan rincian jumlah

\section{REFERENSI}

[1] R. Wijaya and B. Pudjoatmodjo, "Penerapan Extraction-TransformationLoading (ETL) Dalam Data Warehouse (Studi Kasus : Departemen Pertanian)," J. Nas. Pendidik. Tek. Inform., vol. 5, no. 2, p. 61, 2016.

[2] N. Hidayati, "Pentaho Sebagai Solusi Masalah Pengolahan Database," $J$. Transform., vol. 9, no. 2, p. 86, 2012.

[3] M. Hilman and D. Djamaludin, "Analisis Faktor Optimalisasi Proses Etl Pada Data Warehouse Sebagai Pendukung Pengambilan Keputusan Management Dengan Business Intelligence," Fakt. Exacta, vol. 11, no. 1, p. 24, 2018.

[4] P. Dhanda and N. Sharma, "Extract Transform Load Data with ETL Tools," Int. J. Adv. Res. Comput. Sci., vol. 7, no. 3, pp. 152-160, 2016.

[5] Y. Wibisono, Pengantar Pentaho Data Integration ( Kettle), vol. 5. 2014.

[6] F. Zulfikar, Modul Pelatihan Fundamental Of Business Intelligence With Pentaho Community Edition. 2013.

[7] JRP. Mulyana, Pentaho: Solusi Open Source untuk Membangun Data Warehouse. Bandung: Penerbit Andi, 2014.

[8] V. Gour, S. S. Sarangdevot, G. S. Tanwar, and A. Sharma, "Improve Performance of Extract, Transform and Load (ETL) in Data Warehouse," Int. J. Comput. Sci. Eng., vol. 1, no. 3, pp. 786-789, 2010.

[9] S. Darudiato, "Perancangan Data jam kerja per hari dan laporan rekapitulasi jumlah kehadiran dalam sebulan.

\subsection{Saran}

Pada penelitian ini dihasilkan file-file transformasi Pentaho yang mampu menghasilkan laporan sesuai kebutuhan manajemen, namun untuk pengolahan data laporan perbulannya proses masih dilakukan semi manual dengan menjalankan file-file transformasi tersebut secara berurutan, untuk ke depannya bisa ditambahkan job dan user interface agar pengolahan data absensi bisa dilakukan dengan lebih mudah dan user friendly.

Warehouse Penjualan Untuk Mendukung Kebutuhan Informasi Eksekutif Cemerlang Skin Care," Semin. Nas. Inform., vol. 2010, no. UPN Veteran Yogyakarta, pp. 350-359, 2010.

[10] S. Maryam, "KAJIAN PENERAPAN METODE DATA WAREHOUSE ( THE STUDY ON THE APPLICATION OF DATA WAREHOUSE TO MANAGE SPACE SCIENCE DATA )," in Prosiding Seminar Nasional Sains Antariksa, 2016, pp. 263-268.

[11] D. Octavianto and T. Wurijanto, "PENGOLAHAN DATA WAREHOUSE TERHADAP SUMBER DATA AKADEMIK DAN KEMAHASISWAAN STIKOM SEBAGAI SISTEM PENDUKUNG KEPUTUSAN," in Prosiding Seminar Nasional Sistem \& Teknologi Infromasi (SNASTI), 2007, vol. V, pp. 97-100.

[12] Y. Oslan and H. Kristanto, "Proses ETL (Extract Transformation Loading) Data Warehouse untuk Peningkatan Kinerja Biodata dalam Menyajikan Profil Mahasiwa dari Dimensi Asal Sekolah," Res. Fair Unisr, vol. 3, no. 1, 2016.

[13] M. P. Ambara, M. Sudarma, and I. N. Satya Kumara, "Desain Sistem Semantic Data Warehouse dengan Metode Ontology dan Rule Based untuk Mengolah Data Akademik Universitas XYZ di Bali," Maj. Ilm. Teknol. Elektro, vol. 15, no. 1, pp. 8-15, 2016.

[14] K. Khotimah and Sriyanto, "Perancangan Dan Implementasi Data Warehouse Untuk Mendukung Sistem Akademik (Studi 
Kasus Pada Stkip Muhammadiyah Kotabumi)," J. Teknol. Inf. Magister Darmajaya, vol. 2, no. 01, pp. 94-107, 2016.

[15] T. Oktavia, "Perancangan Model Data Warehouse Dalam Mendukung Perusahaan Jasa Pengiriman," in eminar Nasional Informatika (semnasIF), 2011, vol. 2011, no. UPN Veteran Yogyakarta, pp. 93-100.

[16] Mujiono and A. Musdholifah, "Pengembangan Data Warehouse Menggunakan Pendekatan Data-Driven untuk Membantu Pengelolaan SDM," IJCCS (Indonesian J. Comput. Cybern. Syst., vol. 10, no. 1, p. 1, 2016. 